\title{
Emission trading or proportional carbon tax: a quest for more efficacious emission control
}

Masayuki Otaki

\begin{abstract}
Background: Two alternative procedures currently exist for efficient carbon dioxide $\left(\mathrm{CO}_{2}\right)$ emissions control: carbon emission trading and proportional carbon tax. This article explores which of the two is more desirable and efficacious.

Results: Compared to emission trading, the equilibrium under a universal proportional carbon tax achieves Pareto superior allocation. In addition, the price of a unit of $\mathrm{CO}_{2}$ emissions is much higher in the case of a universal proportional carbon tax than for bilateral emissions trading.

Conclusions: This paper reveals the superiority of a universal proportional carbon tax over the emissions trading in terms of the efficiency of $\mathrm{CO}_{2}$ emissions control. However, deciding and abiding by a universal tax rate is likely to require great political will. In this sense, viewed in the current context, such a tax scheme is visionary. Gradualism is unavoidable. It is far more desirable to expand the network of the upcoming trilateral carbon trading network steadily rather than leaving the global economy to the laissez-faire situation.
\end{abstract}

Keywords: $\mathrm{CO}_{2}$ emissions; Proportional carbon tax; Emissions trading; Modified Samuelson Rule; Nonlinear carbon tax

\section{Background}

Carbon markets are jerry-built in nature ${ }^{\mathrm{a}}$. They cannot be sufficiently sustained without government assistance and intervention. According to Lovins and Cohen (2011), p.227, "In the wake of the world's failure to agree on a new trading legislation in Copenhagen and the U.S. Senate failure to pass binding legislation, the price of carbon fell drastically. In the United States it fell almost to nothing. In Europe, the price of carbon fell from a high of $€ 25$ to $€ 8$ a ton. By October 2010, prices had started to rebound, hitting $€ 12$. Subsequent measures have only strengthened the price per ton".

First, this article explores the source of such fragility. We find that the decisions of economic agents emitting carbon dioxide $\left(\mathrm{CO}_{2}\right)$ are isolated from direct and indirect damages due to such emissions, owing to the genuine property of their external diseconomy of the emission; therefore, at the very least, the market cannot remain sustainable without expectations of strengthened regulation in the future.

Correspondence: ohtaki@iss.u-tokyo.ac.jp

Institute of Social Science, University of Tokyo, 7-3-1 Hongo Bunkyo, Tokyo, 113-0033, Japan
Second, we examine the properties of bilateral offset carbon trading, which is currently the most popular trading scheme and is not subject to regulation concerning total emission amounts. Unlike Otaki (2013), although the analysis is static, the extension to dynamic analysis is not impossible, since the latter is an application of cap trading which regulates total emissions. Moreover, analysis pertaining to cap trading, which seems to be popular within the European market, requires the consideration of only one additional constraint concerning total emissions in the model.

Finally, we compare the function of bilateral carbon trading with that of a universal proportional carbon tax. The article concludes that although a wide-ranged universal proportional carbon tax is superior to bilateral carbon trading, the tax rate becomes extremely high and impractical, and hence, expanding the network of bilateral offset emission trading is an efficacious measure for emission trading.

\section{Results and discussions}

The model

Assume that two types of countries exist. One of the countries is an advanced industrialized or developed

\section{Springer}


country which emits $\mathrm{CO}_{2}$. The other country is a developing country that does not emit $\mathrm{CO}_{2}$. There are $n$ pairs of a developed and a developing country $\left(d_{j}, u_{j}\right)$ between which the emission right is traded, where $d_{j}$ and $u_{j}$ are the $j$ th developed and developing country respectively, comprising the $j$ th block of emission trading.

Each country has the same utility function $U_{j}^{i}$ :

$$
\begin{aligned}
U_{j}^{i} & \equiv c_{j}^{i}-\Psi\left(e_{1}^{d}, \cdots, e_{j}^{d}, \cdots, e_{n}^{d}, e_{1}^{u}, \cdots, e_{j}^{u}, \cdots, e_{n}^{u}\right) \\
& \equiv c_{j}^{i}-\Psi\left(\overrightarrow{e^{d}}, \overrightarrow{e^{u}}\right)
\end{aligned}
$$

where $c_{j}^{i}$ and $e_{j}^{i}$ denote the consumption and $\mathrm{CO}_{2}$ emission level of the $j$ th country that belongs to type $i$ $(i=d, u)$, respectively. $\Psi$ represents the disutility from the $\mathrm{CO}_{2}$ emission via the production process of a consumption good. We assume that $\Psi$ is linear homogenous ${ }^{\mathrm{b}}$, quasi concave and symmetric in the following sense. That is,

$$
\Psi\left(. ., e_{l}^{k}, \cdots, e_{l^{\prime}}^{k^{\prime}} . .\right) \equiv \Psi\left(. ., e_{l^{\prime}}^{k^{\prime}}, \cdots, e_{l}^{k} . .\right), \forall k, k^{\prime}, l, l^{\prime} .
$$

This symmetric assumption implies that the disutility derived from the emission does not depend on where it is emitted. It is a plausible assumption when we consider the diffusion speed of $\mathrm{CO}_{2}$ in the atmosphere.

The semi-reduced form production function, which represents the relationship between the consumption $c$ and the adjoined emission $e$, is $c=\alpha F(e), \alpha$ is some positive constant.

$$
F^{\prime}>0, F^{\prime \prime}<0,(e<\bar{e}) . F^{\prime}=F^{\prime \prime}=0,(e \geq \bar{e}) .
$$

That is, $F(\cdot)$ means that if a factory emits $\mathrm{CO}_{2}$ by weight $e$, it produces $c$ units of goods. $\bar{e}$ is the maximal effective $\mathrm{CO}_{2}$ emission in the sense that the emission exceeding this limit bears no additional consumption goods.

We assume that only developed countries possess the production technology. No developing country can access such an opportunity until the bilateral emission trading is settled or some type of proportional carbon tax is levied.

\section{The complete laissez-faire situation}

Assume that, in the laissez-faire situation, the decisions of the production sectors within a country are separated from the consumer sector; they do not consider the nuisance incurred by their emission. Hence, they produce goods amounting to the maximum level $F(\bar{e})$. In such a case, the unit price of carbon is zero.

As noted by Lovins and Cohen (2011), ch.8 and evidenced by history, this fact implies that without government intervention, the carbon market will surely collapse and the unit price of carbon will fall and become negligible.

\section{Unilateral proportional carbon tax: implementation of the} Nash equilibrium

\section{Formatting a unilateral proportional carbon tax}

Moving from the complete laissez-faire situation, each country is separately incentivized to levy a carbon tax to suppress its emissions for its own wellbeing, and thus, a unilateral proportional carbon tax is formatted by the solution of the following optimization problem:

$$
\begin{aligned}
& \max _{e_{l}^{k}} {\left[\alpha F\left(e_{l}^{k}\right)-\Psi\left(e_{l}^{k}, \vec{e}_{l}^{k *}\right)\right], } \\
& \vec{e}_{l}^{k *} \equiv\left(e_{l}^{k^{\prime *}}, \vec{e}_{2}^{*}, \ldots, \vec{e}_{l-1}^{*}, \vec{e}_{l+1}^{*}, \ldots, \vec{e}_{n}^{*}\right), \\
& \vec{e}_{j}^{*} \equiv\left(e_{j}^{d *}, e_{j}^{u *}\right) .
\end{aligned}
$$

Since the solution of this problem satisfies

$$
F^{\prime}\left(e_{l}^{k *}\right)=\left.\frac{1}{\alpha} \cdot \frac{\partial \psi}{\partial c_{1}^{d}}\right|_{\varepsilon_{l}^{k}=\frac{1}{n}}
$$

we find that the allocation implemented by a unilateral carbon $\left.\operatorname{tax} \frac{\partial \psi}{\partial c_{1}^{l}}\right|_{\varepsilon_{j}^{l *}=\frac{1}{n}}$ is identical to that implemented by the Nash equilibrium of an international game of $\mathrm{CO}_{2}$ emission. In this sense, a unilateral proportional carbon tax belongs to a kind of international laissez-faire scheme and does not require any cooperative behavior between countries. However, it is evident that the resource allocation is improved compared with the complete laissez-faire situation, because the equilibrium emissions are determined by weaving the social disutility from excess emissions.

\section{Bilateral emissions trading}

\section{Formatting the bilateral emission trading scheme}

Bilateral emissions trading between the developed and the developing country in the $j$ th pair is defined by the following optimization problem. That is,

$$
\begin{aligned}
\max _{e_{j}^{d}, e_{j}^{u}, P}\left\{\left[\alpha F\left(e_{j}^{d}\right)\right.\right. & +\alpha F\left(e_{j}^{u}\right)-P \\
& \left.-\Psi\left(e_{j}^{d}, e_{j}^{u}, e_{1}^{d *}, e_{1}^{u *} \cdots e_{n}^{d *}, e_{n}^{u *}\right)\right] \\
& \left.+\lambda\left[P-\Psi\left(e_{j}^{u}, e_{j}^{d}, e_{1}^{d *}, e_{1}^{u *} \cdots e_{n}^{d *}, e_{n}^{u *}\right)-\bar{U}\right]\right\},
\end{aligned}
$$

where $P$ is the total payment for the carbon emissions. * denotes the optimal contract emissions of the other pairs. $\lambda$ is the Lagrangean multiplier of this problem. $\bar{U}$ denotes the reservation utility of the corresponding 
developing country. The above constrained maximization problem means that an advanced country maximizes its economic welfare guaranteeing the minimal utility level of the counterpart developing country at the level of $\bar{U}$. The first term of (6) is the developed-country's utility derived from this emission trading, and the term within the square brackets of the second term is the net welfare gain of the developing country.

Let us denote

$$
\varepsilon_{j}^{l} \equiv \frac{e_{j}^{l}}{\sum_{l, k=1}^{n} e_{k}^{l}} \equiv \frac{e_{j}^{l}}{E}
$$

By using $\varepsilon_{j}^{l}$ and $E, \Psi$ can be transformed into

$$
\Psi=\psi\left(\overrightarrow{\varepsilon^{d}}, \overrightarrow{\varepsilon^{u}}\right) E \equiv \psi(\vec{\varepsilon}) E .
$$

Then by the symmetry of $\Psi$, the optimality condition for the above contract problem under perfect information and symmetric equilibrium can be represented as

$$
\begin{aligned}
F^{\prime}\left(e_{l}^{k *}\right)=\left.\frac{2}{\alpha} \cdot \frac{\partial \psi}{\partial c_{1}^{l}}\right|_{\varepsilon_{j}^{l *}=\frac{1}{n}} \equiv \frac{\theta(2)}{\alpha} \cdot \forall j, l . \\
\begin{aligned}
P^{*}=\bar{U}+\Psi\left(\overrightarrow{e^{*}}\right)= & \bar{U}+\theta(2) \cdot n e^{*} \\
= & \bar{U}+\theta(2) \cdot e^{*}+[n-1] \theta(2) \cdot e^{*} \equiv \bar{U}+T(2) \\
& +[n-1] \theta(2) \cdot e^{*} .
\end{aligned}
\end{aligned}
$$

$\left.\theta(2) \equiv 2 \frac{\partial \psi}{\partial c_{1}^{l}}\right|_{\varepsilon_{j}^{l *}=\frac{1}{n}}$ is the unit carbon price in this trading scheme.

This scheme can be regarded as the ideal offset-trade scheme. The carbon price should be determined as the sum of the marginal disutility from the global warming of two countries with partnership. The transfer from a developed country is, aside from the direct payment for carbon emissions $T(2)$, the sum of the reservation utility of the developing country in concern $\bar{U}$ and the pecuniary nuisance from emissions of other developed countries as a whole $[n-1] \theta(2) \cdot e^{*}$.

We must note that such an ideal system does not require setting the baseline of the project, which is unavoidable in the current system. Since the procedures for such setting is very much complicated and lapses much time, it seems to be desirable to transform the existing offset trading scheme to that based on the formulae (9) and (10).

\section{Universal proportional carbon tax}

\section{Formatting a universal proportional carbon tax scheme}

A universal proportional carbon tax is formatted by the following optimization problem:

$\max \vec{\varepsilon}\left[\alpha F\left(e_{1}^{d}\right)-\Psi(\vec{\varepsilon}) E+\sum_{(l, k) \neq(1, d)} \lambda_{l}^{k}\left[\alpha F\left(e_{l}^{k}\right)-\Psi(\vec{\varepsilon}) E-\bar{U}^{m}\right]\right]$.

The above problem means that an advanced country maximizes its economic utility presuming it provides the rest of the world with the minimal utility $\bar{U}$. It is clear that the attained allocation under such a scheme is Pareto efficient by definition. By the symmetry of the problem, it is also clear that every Lagrangean multiplier under optimal planning takes the value unity ${ }^{c}$. Thus, we obtain the following formula concerning the optimal emission:

$$
F^{\prime}\left(e^{*}\right)=\left.\frac{n}{\alpha} \frac{\partial \psi}{\partial c_{1}^{d}}\right|_{e_{j}^{l *}=\frac{1}{n}} .
$$

This is the modified Samuelson (1954) rule concerning the optimal public good (bad) provision: The marginal benefit accrued from the country's emissions $\alpha F^{\prime}\left(e^{*}\right)$ should be equalized to the sum of the marginal disutility diffused all over the world, $\left.n \frac{\partial \psi}{\partial c_{1}^{d}}\right|_{\varepsilon_{j}^{l *}=\frac{1}{n}}$. The right-hand side of (12) is the optimal tax rate common to all constituents.

Welfare ordering for various emission suppressing measures Although it is clear that a proportional carbon tax, with the rate expressed by (12), is the first-best policy, it is important to understand the manner in which the other two measures are ordered in terms of Pareto efficiency. We can deal with this problem by using the symmetry and linear homogeneity of $\Psi$.

The utility of each country $U_{l}^{k}$ can be written as

$$
\begin{aligned}
U_{l}^{k}(j) & =\alpha F\left(e^{*}(j)\right)-\left.\frac{\partial \psi}{\partial c_{1}^{l}}\right|_{\varepsilon_{l}^{k *}=\frac{1^{*}}{n}} \cdot E^{*}(j) \\
& =\alpha F\left(e^{*}(j)\right)-\left.n \frac{\partial \psi}{\partial c_{1}^{l}}\right|_{\varepsilon_{l}^{k^{*}}=\frac{1^{*}}{n}} \cdot e^{*}(j) .
\end{aligned}
$$

Employing the envelop theorem,

$$
\begin{aligned}
& \frac{d U_{l}^{k}(j)}{d j}=\left.\frac{\partial \psi}{\partial c_{1}^{l}}\right|_{\varepsilon_{l}^{k}=\frac{1}{n}} \cdot e^{*}(j)>0,(1 \leq j<n) \\
& \frac{d U_{l}^{k}(j)}{d j}=0,(j=n) \\
& \frac{d U_{l}^{k}(j)}{d j}=\left.\frac{\partial \psi}{\partial c_{1}^{l}}\right|_{\varepsilon_{l}^{k}=\frac{1}{n}} \cdot e^{*}(j)<0,(n<j)
\end{aligned}
$$

holds. Thus, it is clear from the above equations that the bilateral emission trading scheme Pareto-dominates a 
unilateral carbon tax scheme, whereby a country can set a proportional carbon tax rate at its discretion.

This fact implies that although a proportional carbon tax possibly attains the first-best allocation, emission trading is the second-best measure, unless all countries concur about the seriousness of global warming, in which case a much higher carbon tax rate than that in the unilateral case can be adopted. In addition, since $n$ is likely to far exceed two, the suppression effect of emission trading is estimated to be rather restrictive from the view point of the first-best allocation.

\section{Welfare analysis of emission-saving technological progress}

Consider the effect of emission-saving technological progress to the world economy as a whole. This progress is expressed by an increase in $\alpha$ in this model. Before proceeding to the general equilibrium analysis, we must note that every trading pair increases emissions in conjunction with technological progress. Although it seems to be counterintuitive, if we note the fact that technological progress makes the imputed price of $\mathrm{CO}_{2}$ cheaper as shown by the right-hand sides of (5), (9), and (12), it is natural that emission-saving technological progress conversely heightens the accumulation of $\mathrm{CO}_{2}$.

With this precaution in mind, we shall proceed with the general equilibrium analysis, into which the mutual negative externalities between trading pairs are woven. Then, from (13) and the envelop theorem, we obtain

$$
\begin{gathered}
\frac{d U_{j}^{d}}{d \alpha}=F\left(e^{*}\right)-\left.[n-j] \frac{\partial \psi}{\partial e_{1}^{d}}\right|_{\varepsilon_{l}^{k}=\frac{1}{n}} \frac{d e^{*}}{d \alpha}>\frac{1}{\alpha}\left[\alpha F\left(e^{*}\right)-\eta \Psi\right], \\
\eta \equiv \frac{e^{*} / e^{*}}{d \alpha / \alpha}, \forall j, \quad \frac{d U_{n}^{d}}{d \alpha}>0,
\end{gathered}
$$

where $\eta$ is the elasticity of the emission volume to the unit of the technological progress. Since $\alpha F\left(e^{*}\right)-\Psi>0$, if $\eta$ is small enough and the increase in the emission generated by the technological progress is not so serious ${ }^{\mathrm{d}}$, the advance in the emission-saving technology improves worldwide utility, although this advance also increases the total amount of $\mathrm{CO}_{2}$ emissions. This fact is underscored in that when we extend the scope of analysis to dynamic and intergenerational emission allocation (e.g., Otaki 2013), we may have to modify the obtained result, because the acceleration in emissions diffuses the negative externality to future generations.

In other words, although the emission-saving technological progress lowers the imputed price of $\mathrm{CO}_{2}$ and stimulates the current generation's consumption, such current prosperity may conversely worsen the descendants' utility via the resulting massive emissions.
However, such a dynamic prospect is beyond of the scope of this article, and itself requires solving the simultaneous optimization concerning intertemporal and international emission problems.

\section{On income distribution between countries: the possibility of nonlinear pricing}

Thus far, this article has assumed that a developed country directly invests in the corresponding developing country and that it receives revenues after deducting the carbon tax. Thus,

$$
\alpha F\left(e^{*}(j)\right)-\left.j \cdot \frac{\partial \psi}{\partial e_{1}^{l}}\right|_{\varepsilon_{l}^{k}=\frac{1}{n}} \cdot e^{*}(j) \equiv \alpha F\left(e^{*}\right)-\tau(j) \cdot e^{*}(j),
$$

where $\tau_{j}$ is the carbon tax rate, which is identical to the unit carbon price in emission trading. Hence, the developing country obtains tax revenues $R(j)$, which amount to

$$
R(j) \equiv \tau(j) \cdot e^{*}(j)
$$

from the investing developed country.

Since every constraint concerning the joint utility from such a trading scheme binds whenever planning is optimal (see Uzawa 1958), the net surplus from the trading in terms of consumption becomes $\bar{U}^{m}$ e Although we have not yet analyzed the possibility of additional lumpsum transfer from the investing developed country to its counterpart developing country (or the transfer inverted direction, which is possible if the tax payment is too heavy for the developed country), one cannot envisage a universal proportional carbon tax without some fair division of the surplus earned by direct investment through this lump-sum transfer, specifically because the standard of living of the remitting / recipient country depends decisively on its share of this surplus (Uzawa 2003).

Hereafter this article analyzes both directions of the transfer and clarifies how the direction affects the effective tax rate. First, consider the transfer from the developed country to the developing country. This is an application of nonlinear pricing, which appears in basic microeconomics (e.g., see Tirole 1988). Let the sum of the transfer be $s$. Then, the total payment of a developed country to her counterpart $T$ becomes

$$
T \equiv \tau(j) e(j)+s=\left[\tau(j)+\frac{s}{e(j)}\right] \cdot e(j) .
$$

The term within the square brackets is the effective tax rate, which is illustrated by Figure 1. Thus, the effective tax rate is digressive although such a transfer enriches the developing country. This is owing to the economy of scale from the de-facto massive purchase of the right of emission. 


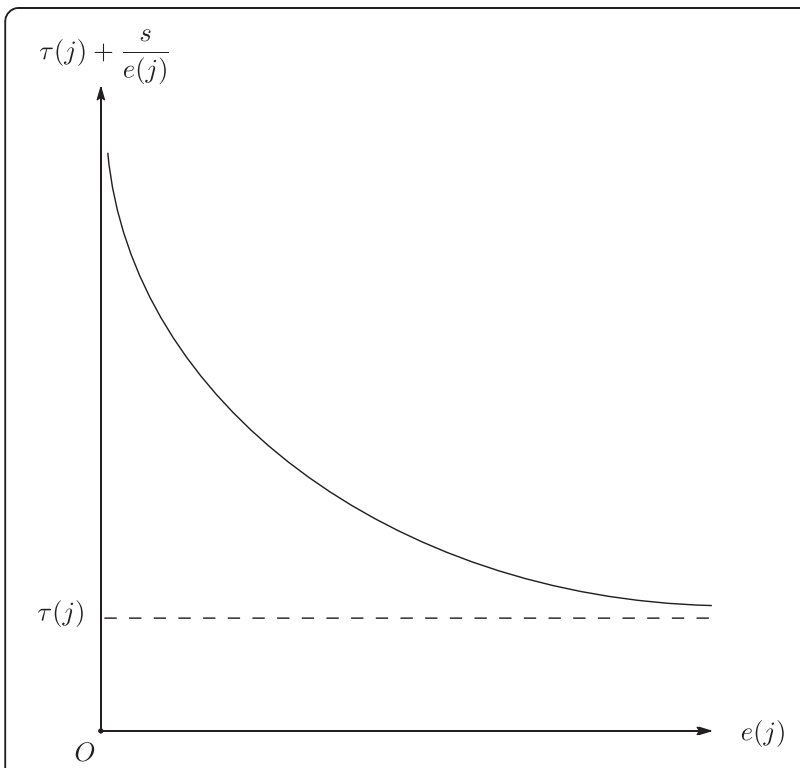

Figure 1 The effective tax rate (Digressive Case: $s>0$ ).

Figure 2 illustrates the locus of the effective tax rate for the inverted transfer from the developing country to the developed country $(s<0)$. It is apparent that the effective tax rate becomes progressive despite impoverishing the developing country. The progressive effective tax rate owes its existence entirely to the diseconomy of scale concerning emissions. However, we must still note that whether the effective tax rate is progressive or otherwise does not affect the efficacy of emission allocation. Moreover, this discussion exemplifies that the progressive tax

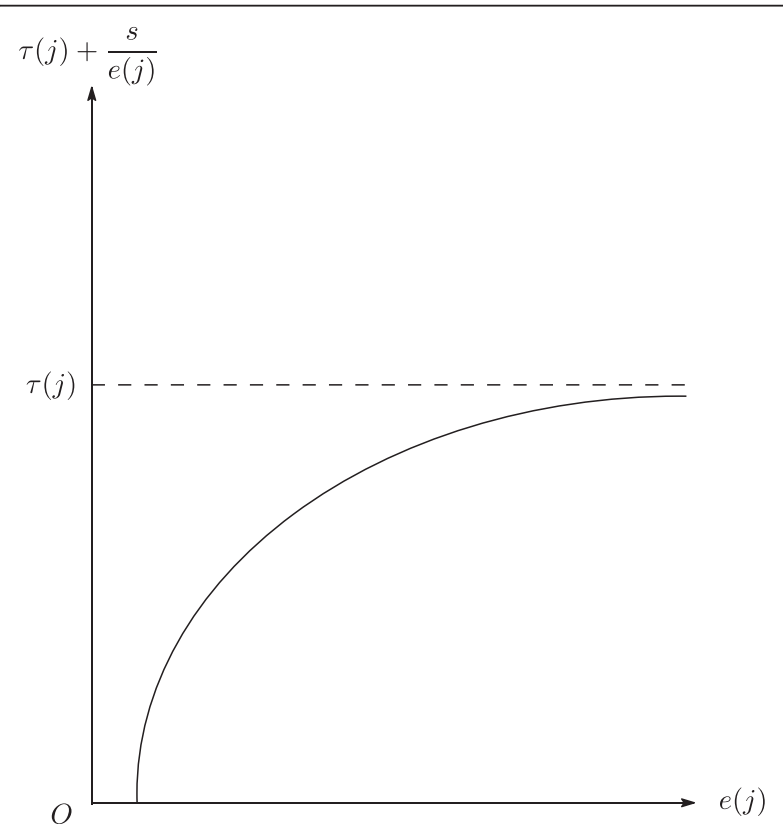

Figure 2 The effective tax rate (Digressive Case: $s<0$ ). rate is not necessarily advantageous to the developing country.

\section{Conclusions}

This article compared the static efficiency of the consumption/emission allocation of three alternative emission control measures (proportional carbon tax (unilateral or universal) and emission trading). A unilateral carbon tax, akin to a symmetric Nash equilibrium of the worldwide consumption/emission game, is less efficient than bilateral carbon emission trading. Although a universal proportional carbon tax, into which the entire negative externalities of the emissions of a country are woven, achieves the Pareto efficient allocation, realizing such an ideal tax system at this time appears very difficult. That is because the tax rate would become extremely high, much higher than the incumbent tax rate or price of emission right. As such, gradualism seems inevitable. The transition from bilateral to multilateral emission trading is desirable. Thus, a universal proportional carbon tax should be considered as the ultimate solution, and an enabling political arena is needed to gradually establish the system.

Finally, it is inevitable that an emission-saving technological progress stimulates not only consumption but also emissions. Such technological progress cheapens the imputed price of $\mathrm{CO}_{2}$. Although this possibly bodes well for the current generation, it accelerates $\mathrm{CO}_{2}$ accumulation and translates into a negative inheritance for our descendants.

\section{Methods}

Three measures for suppressing $\mathrm{CO}_{2}$ emission are compared from the viewpoint of Pareto efficiency: a unilateral proportional carbon tax, a bilateral or trilateral emission trading, and a universal proportional carbon tax. Heightened consumption within a country increases its utility at the cost of scattering more voluminous $\mathrm{CO}_{2}$ all over the world and accelerating global warming. In this sense, there is a serious trade-off between consumption and $\mathrm{CO}_{2}$ emissions, and thus this induces excess consumption/emission owing to the negative externalities, which are inherent to emissions.

The above three measures are modeled using a basic social planning theory under certainty, and are developed for suppressing excessive economic activity. The characteristics of these measures are classified by the extent of the negative externalities that a developed country cares to address when it emits $\mathrm{CO}_{2}$. A unilateral proportional carbon tax scheme is only concerned with the country's own disutility from its emissions. A bilateral or trilateral emission trading scheme limits the country's concern to itself and its counterpart developing country, while a universal proportional carbon tax 
requests each affiliate to calculate the worldwide disutility caused by its emissions.

\section{Endnotes}

${ }^{\mathrm{a}}$ United States Environmental Protect Agency (2003) classified emission trading into three categories: (i) cap and trade, (ii) project-based trade, (iii) rate-based trade. The offset trade is corresponds to the second category. My analysis concentrates and theorizes this category of emission trade. Offset Quality Initiative (2008) indicates how the quality of emission offsetting measure is assessed.

United Nations Framework Convention on Climate Change (2012) figures out how the clean development mechanism (CDM) actually works.

${ }^{\mathrm{b}}$ The linear homogeneity assumption is introduced by facilitating the calculation. We can easily extend the class of $\Psi$ into the homothetic function. However, we need additional information on $\Psi$.

${ }^{\mathrm{c}}$ The first-order condition requires that $\alpha \lambda_{l}^{k} F^{\prime}\left(e_{l}^{k *}\right)$ $=\left.\left[1+\sum_{j \neq l, k} \lambda_{j}^{k}\right] \frac{\partial \Psi}{\partial \varepsilon_{1}^{d}}\right|_{\varepsilon_{j}^{k}=\frac{1}{n}}$. Accordingly, $\lambda_{j}^{k}=1, \forall j, k$ satis-

fies this condition. If $\lambda_{j^{\prime}}^{k^{\prime}} \neq 1$ for some $p$ pairs of $\left(j^{\prime \prime}, k^{\prime \prime}\right), \frac{1}{\lambda_{s^{\prime \prime}}^{k^{\prime \prime}}}$ $\left[1+\sum_{j, k} \lambda_{j}^{k}\right]=1+\frac{n-p+\sum_{\left(j^{\prime}, k^{\prime}\right) \neq\left(j^{\prime \prime}, k^{\prime \prime}\right)} \lambda_{j^{\prime}}^{k^{\prime}}}{\lambda_{s^{\prime \prime}}^{k^{\prime \prime}}}$ holds for $\left(j^{\prime \prime}, k^{\prime \prime}\right)$.

Otherwise $\frac{1}{\lambda_{l}^{k}}\left[1+\sum_{j \neq l, k} \lambda_{j}^{k}\right]=[n-p]+\sum_{\left(l^{\prime}, k^{\prime}\right)} \lambda_{s^{\prime}}^{k^{\prime}}$ holds. Let us define $S_{p} \equiv \sum_{\left(l^{\prime \prime}, k^{\prime \prime}\right)} \lambda_{s^{\prime \prime}}^{k^{\prime \prime}}$. Then, the symmetric assumption requires $1+\frac{n-p+S_{p}-\lambda_{s^{\prime \prime}}^{k^{\prime \prime}}}{\lambda_{s^{\prime \prime}}^{k^{\prime \prime}}}=[n-p]+S_{p} \Rightarrow \lambda_{s^{\prime \prime}}^{k^{\prime \prime}}=1$. This is a contradiction. Therefore, $\lambda_{l}^{k}=1, \forall l, k$.

${ }^{\mathrm{d}}$ Otherwise, the welfare is conversely aggravated by the emission-saving technological progress under second-best emission control systems. This is a fallacy of composition.

${ }^{\mathrm{e}} \mathrm{Since}$ our utility function is quasi linear, the surplus is equivalent to that in terms of the utility. In addition, since we presume that the equilibrium is symmetric, the reservation utility $\bar{U}^{m}$ is endogenously determined. This result comes from the required property that all optimal Lagrangean multipliers should take the value unity.

${ }^{\mathrm{f}}$ This article studies how far emissions of $\mathrm{CO}_{2}$ are permissible with the remaining given volume of $\mathrm{CO}_{2}$ in the atmosphere. As such, estimating the dynamic and cumulative effects of $\mathrm{CO}_{2}$ is beyond the scope of this article. While Otaki (2013) considered this problem, he neglected the problem of the efficient allocation of emissions on an international basis.

\section{Competing interests}

The author declares that he has no competing interests.

\section{Acknowledgements}

The author is thankful to Susumu Cato and Morio Kuninori for their incisive and constructive comments.

Received: 3 August 2013 Accepted: 15 October 2013

Published: 18 October 2013

\section{References}

Lovins L, Cohen B (2011) Climate capitalism: capitalism in the age of climate change. Hill and Wang, NY

Offset Quality Initiative (2008) Ensuring offset quality: integrating high quality greenhouse gas offsets in North American cap-and-trade policy. http://www. offsetqualityinitiative.org/pdfs/OQI_Ensuring_Offset_Quality_Exec_Sum_7_08.pdf

Otaki M (2013) Endogenous social discount rate, proportional carbon tax, and sustainability: do we have the right to discount future generations' utility? Environ Syst Res 2: 10.1186/2193-2697-2-1

Samuelson P (1954) The pure theory of public expenditure. Rev Econ Stat $36: 387-389,10.2307 / 1925895$

Tirole J (1988) The theory of industrial organization. MIT Press, Massachusetts

United States Environment Protection Agency (2003) Tools of the trade: a guide to designing and operating a cap and trade program for pollution control. EPA430-B-03-002. http://www.epa.gov/airmarkets/resource/docs/tools.pdf

United Nations Framework Convention on Climate Change (2012) Clean Development Mechanism: Executive Board Annual Report 2012. http:// unfccc.int/resource/docs/publications/pub_cdm_eb_annual_report_2012.pdf

Uzawa H (1958) The Kuhn-Tucker theorem in concave programming. In: Arrow K, Harwich L, Uzawa H (eds) Studies in linear and nonlinear programming. Stanford University Press, California, pp 129-134

Uzawa H (2003) Economic theory and global warming. Cambridge University Press, Cambridge

doi:10.1186/2193-2697-2-8

Cite this article as: Otaki: Emission trading or proportional carbon tax: a quest for more efficacious emission control. Environmental Systems Research 2013 2:8.

\section{Submit your manuscript to a SpringerOpen ${ }^{\circ}$ journal and benefit from:}

- Convenient online submission

- Rigorous peer review

- Immediate publication on acceptance

- Open access: articles freely available online

- High visibility within the field

- Retaining the copyright to your article

Submit your next manuscript at $>$ springeropen.com 